\title{
Renewable and Sustainable Transportation Fuels
}

\section{Siqing Liu*}

National Center for Agricultural Utilization Research, USA

Sugarcane-based ethanol has been the major automobile fuel in Brazil for over three decades due to the abundant and renewable production of cane sugar. A $10 \%$ blend of corn starch-based ethanol with gasoline, also known as E10 or gasohol, is used in most cars running on US roads today. Legislation like the Energy Independence and Security Act of 2007 has led to an aggressive expansion of starch to ethanol production in the US, growing from 175 million gallons in 1980 to 13.9 billion gallons in 2011 (http://www.ethanolrfa.org).

Currently a total of 17 states in the US use bio-ethanol to replace methyl tert-butyl ether (MTBE) as a safer oxygenate for gasoline formulations (www.eia.gov ). Moreover, E15 (15\% ethanol blend) was recently approved by the U.S. Environmental Protection Agency for use in select automobiles from 2001 and newer model years, and in all flexible fuel vehicles (FFVs). It has been projected that in the US by the year 2035, 63\% of the bio-ethanol produced in the US will be used for E10 and E15, while 37\% will be used in FFVs operating on E85 (85\% ethanol blended with $15 \%$ gasoline), which should significantly reduce US consumption of petroleum- based transportation fuel (http://www. eia.gov/forecasts/aeo/MT_liquidfuels.cfm).

Starch based ethanol, also known as a "first generation" biofuel, has been accepted as a commodity in the fuel market, which supplies fuel to almost all of the E10, E15 and E85 vehicles currently on US roads. However, using corn starch for ethanol could potentially compete with food, feed and fiber resources. Thus, lignocellulosic biomass materials have been recognized as alternative feedstocks for ethanol production since the 1970s [1]. From the 1970s to late 1990s, pioneering research in the area of biomass pretreatment and conversion to liquid fuels showed progress [2-6], but in the last decade, research converting biomass to biofuels has been pursued extensively. As demonstrated in figure 1 a significant increase in funding and publications was observed after 2002, the year when the US Department of Energy's Biomass Program started.

Technologies and processes for cellulosic ethanol, known as a "second generation" biofuel, have been developed and feasibility tests have been successful at pilot plants. To date, seven commercial cellulosic plants are under construction in the US although cost-competitive

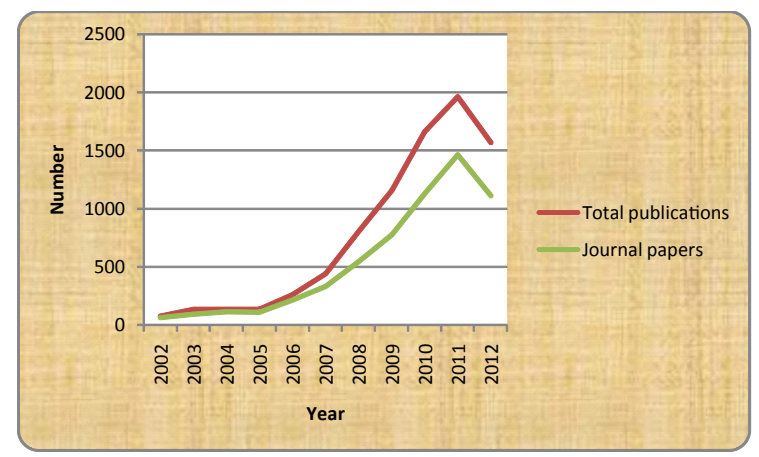

Figure 1: The total number of publications in the area of biomass and biofuels per year is presented here. The data was collected from 2002 to September, 2012 from a search of the CAS database (http://www.cas.org/ products/scifinder) using keywords "biomass" and "biofuels". production remains a grand challenge (http://en.wikipedia.org/wiki/ Cellulosic_ethanol_commercialization).

The most abundant and renewable lignocellulosic biomass materials contain not only cellulose, but also lignin and hemicelluloses in a complex and recalcitrant structure [7]. Lignocellulosic biomass from agricultural and forestry residues, energy crops, and municipal waste are renewable and sustainable resources. The development of "third generation" biofuels and bio-based replacements of petroleum products including jet fuel, gasoline, polymers and chemical feedstocks from lignocellulosic materials will widen the biomass to bioenergy field. Evidently more innovative research and technologies are needed to create a sustainable bioenergy industry and to reduce US dependence on imported petroleum.

\section{References}

1. Wang DIC, Biocic I, Fang HY, Wang SD (1977) Presented at the Proceedings of the Third Annual Biomass Energy Systems Conference, Solar Energy Research Institute, Department of Energy, Washington, DC, USA.

2. Flickinger MC (1980) Current biological research in conversion of cellulosic carbohydrates into liquid fuels: how far have we come? Biotechnol Bioeng 22: 24-48.

3. Ho NW, Chen Z, Brainard AP (1998) Genetically engineered Saccharomyces yeast capable of effective cofermentation of glucose and xylose. Appl Environ Microbiol 64: 1852-1859.

4. Ingram LO, Conway T, Clark DP, Sewell GW, Preston JF (1987) Genetic engineering of ethanol production in Escherichia coli. Appl Environ Microbiol 53: $2420-2425$.

5. Lawford HG, Rousseau JD (1993) Production of ethanol from pulp mill hardwood and softwood spent sulfite liquors by genetically engineered $\mathrm{E}$. coli. Appl Biochem Biotechnol 39-40: 667-685.

6. Zhang M, Franden MA, Newman M, McMillan J, Finkelstein M, et al. (1995) Promising Ethanologens for Xylose Fermentation. Appl Biochem Biotechnol 51-52: 527-536.

7. Saha BC (2003) Hemicellulose bioconversion. J Ind Microbiol Biotechnol 30 279-291.

*Corresponding author: Siqing Liu, USDA-ARS-NCAUR, 1815 N University, Peoria, IL 61604, USA, E-mail: Siqing.liu@ars.usda.gov

Received October 26, 2012; Accepted October 26, 2012; Published October 30 , 2012

Citation: Liu S (2012) Renewable and Sustainable Transportation Fuels. J Pet Environ Biotechnol 3:e115. doi:10.4172/2157-7463.1000e115

Copyright: (c) 2012 Liu S. This is an open-access article distributed under the terms of the Creative Commons Attribution License, which permits unrestricted use, distribution, and reproduction in any medium, provided the original author and source are credited. 